\title{
Low Bone Turnover in Chronic Kidney Disease Is Associated with Decreased VEGF-A Expression and Osteoblast Differentiation
}

\author{
Neal X. Chen ${ }^{a}$ Kalisha D. O'Neill ${ }^{a}$ Matthew R. Allen ${ }^{a, c}$ \\ Christopher L. Newman ${ }^{c}$ Sharon M. Moe ${ }^{a, b}$ \\ ${ }^{a}$ Department of Medicine, Indiana University School of Medicine, ${ }^{b}$ Roduebush Veterans Affairs Medical Center, and \\ 'Department of Anatomy and Cell Biology, Indiana University School of Medicine, Indianapolis, Ind., USA
}

\section{Key Words}

VEGF $\cdot$ CKD $\cdot$ Bone marrow cells $\cdot$ Bone formation $\cdot$ PTH

\begin{abstract}
Background: Low turnover bone (low bone formation rates (BFRs)) with decreased osteoblast number is common in patients with chronic kidney disease (CKD) and attributed to 'over-suppression' of the parathyroid hormone (PTH) despite supra-physiologic levels. An alternative hypothesis is abnormal osteoblast differentiation, resulting in low BFRs due to reduced VEGF-A. Methods: We analyzed the expression of VEGF-A and mesenchymal stem cell (MSC) differentiation factors in freshly isolated bone marrow (BM) cells, and in BM cell-derived MSC in rats with different levels of BFRs and PTH (modulated by calcium and zoledronic acid). The regulators of VEGF in MSC were also determined. Results: VEGF-A expression was reduced in the BM cells from CKD vs. normal animals ( $p<0.02$ ). In BM-derived MSC from CKD, there were decreased osteoblast transcription factors and mineralization. In CKD animals, the BM VEGF-A expression was positively correlated with BFR ( $r=0.80, p<0.001)$. Reducing BFRs in CKD animals led to reductions in VEGF-A expression and osteoblast transcription factors regardless of the PTH level. We therefore examined other regulators of VEGF-A and found decreased expression of hypoxia-inducible factor-1 $a$ and the master transcription factor of antioxi-
\end{abstract}

dants nuclear factor (erythroid-derived 2)-like 2 in CKD animals with low PTH. Conclusion: Low BFRs in CKD are associated with a basal decrease in VEGF-A expression in BM that may be driven by altered hypoxia and oxidative stress.

(c) 2015 S. Karger AG, Base

\section{Introduction}

CKD is associated with increased fracture rates [1-4]. Abnormal bone remodeling is a major determinant of this increased fracture rate and can be assessed by histomorphometry with dynamic measures using tetracycline labeling. In $\mathrm{CKD}$, high turnover bone disease (high bone formation rates (BFRs)) has been associated with elevated PTH, and low turnover disease (low BFRs) has been associated with 'over suppression' of PTH [5]; yet, levels often remain greater than normal levels in the general population. Studies in the 1970s demonstrated skeletal resistance to $\mathrm{PTH}$ in patients with CKD [6] and, until recently, PTH was thought to be the primary bone hormone involved in this disease. However, there is now increased understanding of the complexity of bone differentiation, osteoblast-osteoclast cross talk, the impor-

Institute where work done: Indiana University School of Medicine.

\section{KARGER 125}

(c) 2015 S. Karger AG, Basel

$0250-8095 / 15 / 0416-0464 \$ 39.50 / 0$

E-Mail karger@karger.com

www.karger.com/ajn
Neal X. Chen, $\mathrm{PhD}$

Associate Research Professor of Medicine

Division of Nephrology, Indiana University School of Medicine

950 W. Walnut Street; R2-202, Indianapolis, IN 46202 (USA)

E-Mail xuechen@iu.edu 
Table 1. Serum biochemistry and bone parameters in CKD rats treated with calcium or zoledronic acid

\begin{tabular}{llllll}
\hline \multirow{2}{*}{ Treatment } & \multicolumn{2}{l}{ Serum biochemistry } & & & Histomorphometry \\
\cline { 2 - 3 } & calcium & phosphorus & PTH & & BFR/BS (BFR) \\
\hline CKD-control $(\mathrm{n}=10)$ & $\leftrightarrow$ & $\uparrow$ & $\uparrow \uparrow$ & $\uparrow \uparrow *$ \\
CKD-low PTH/calcium treated $(\mathrm{n}=10)$ & $\uparrow$ & $\uparrow$ & $\uparrow$ & $\downarrow$ & $\downarrow \downarrow$ \\
CKD-zoledronic $(\mathrm{n}=10)$ & $\leftrightarrow$ & $\uparrow$ & $\uparrow \uparrow$ & $\downarrow \downarrow$ \\
\hline
\end{tabular}

$* \uparrow \uparrow, \downarrow \downarrow, \leftrightarrow$ compare to normal animals; data adapted from [1].

tance of the osteocyte in facilitating cell-cell communication, and the role of the bone marrow (BM) microenvironment $[7,8]$. These advances increase the possibility that low BFRs in patients with CKD may represent an inherent defect in bone cell differentiation or cell signaling rather than a direct result of lowering PTH levels. This hypothesis may also explain why normal or slightly elevated PTH levels may be associated with low BFRs in patients with CKD.

Osteoblasts, which are key cells in bone formation, differentiate from marrow derived mesenchymal stem cells (MSCs) via regulation by multiple factors [8]. With aging [9], and in CKD [10], MSC preferentially differentiate to adipocytes rather than osteoblasts, leading to increased marrow fat and low BFRs. One regulator of normal osteoblast differentiation is vascular endothelial growth factorA (VEGF-A) [11]. While initially identified as a key regulator of endochondral ossification [12], VEGF-A and its receptors (VEGF-R1 (Flt-1), VEGF-R2 (KDR)) are highly expressed in osteoblasts and VEGF-A dose dependently stimulates chemotactic migration and proliferation of primary human osteoblasts $[13,14]$. In mouse models, aging is associated with decreased VEGF-A expression in MSC [15]. Studies have demonstrated that PTH can regulate the expression of VEGF in vitro and in vivo $[16,17]$. VEGF-A is also regulated by both hypoxia and oxidative stress, mediated by HIF-1 $\alpha$ (hypoxia-inducible factor- $1 \alpha$ ) $[18,19]$ and Nrf-2 (nuclear factor (erythroid-derived 2)like 2) [20], respectively. Therefore, the goals of this study were to test the hypotheses that (1) altered VEGF-A expression in CKD is associated with decreased BFRs and (2) increased PTH would result in normalization of altered VEGF-A expression and increased BFRs.

\section{Materials and Methods}

Animal Model and Experimental Design

This study examined BM cells obtained at the time of sacrifice from male $\mathrm{Cy} /+$ rats, Han:SPRD rats due to a missense mutation in the SamCystin (ANKS6) gene [21]. In the rat, this transmits polycystic kidney disease in an autosomal dominant manner rather than the autosomal recessive nephronophthisis in humans [22]. The $\mathrm{Cy} /+$ rat, hereafter called CKD, spontaneously develops all 3 manifestations of CKD-mineral bone disorder: biochemical abnormalities, extra skeletal calcification, and abnormal bone [23, 24]. The CKD rats, if untreated, develop secondary hyperparathyroidism and increased BFRs. However, the BFRs can be suppressed with either calcium (that also lowers $\mathrm{PTH}$ ) or the bisphosphonate zoledronic acid $[1,25]$.

For this study, we compared BM cells isolated and analyzed at the time of sacrifice to directly compare BM originating from CKD versus normal (NL) animals. We also isolated MSC from these BM cells to determine differentiation potential (via culture) in NL and CKD animals. The study design, biochemical, and bone histomorphometry methods and results were previously reported [1] and are summarized in table 1 . In brief, male heterozygote $\mathrm{Cy} /+(\mathrm{CKD})$ animals ( $\mathrm{n}=10$ each group) were started treatment at 25 weeks for 10 weeks and received ( 1 ) no treatment (control CKD $=$ high PTH and high BFR), (2) received 3\% calcium in the drinking water $(\mathrm{CKD} /$ calcium group $=$ low $\mathrm{PTH}$ and low BFR), or (3) received a single injection of zoledronic acid $(\mathrm{CKD} /$ zoledronic group $=$ high PTH and low BFR). These groups allowed us to analyze how differences in VEGF signaling and MSC differentiation relate to BFR distinct from PTH levels. All procedures were reviewed and approved by the Indiana University School of Medicine Institutional Animal Care and Use Committee.

\section{Isolation of BM Cells and Culture of MSC}

At the time of euthanasia, BM cells were collected using published protocols [26]. BM cells collected from tibia and femur were flushed with ice-cold a-MEM media (Gibco, Grand Island, N.Y., USA) and centrifuged to pellet BM cells for RNA isolation to compare CKD versus NL animal VEGF-A and VEGF receptor expression. For MSC cultures, BM cells from tibia and femur from NL and CKD animals were cultured in a-MEM and 10\% FBS. Nonadherent cells were removed by replacing the medium after 3 days. Adherent cells were further cultured in a-MEM with $10 \% \mathrm{FBS}$ and $50 \mu \mathrm{g} / \mathrm{ml}$ ascorbic acid to obtain a homogenous population of MSC for use in the experiments. To induce osteogenesis, MSC were seeded at $1 \times 10^{4}$ cells $/ \mathrm{cm}^{2}$ and cultured in a-MEM with $10 \%$ FBS containing $50 \mu \mathrm{g} / \mathrm{ml}$ ascorbic acid, $10 \mathrm{mM} \beta$-glycerophosphate and $10 \mathrm{nM}$ dexamethasone for 21 days [27]. For adipogenic differentiation, MSC were incubated in $\alpha$-MEM with $10 \%$ FBS containing $1 \mu \mathrm{M}$ dexamethasone and $0.5 \mathrm{mM}$ 3-isobutyl-1-methylxanthine (IBMX, Sigma, St. Louis, Mo., USA) for 21 days [27]. Media was changed every 3 days. 
Real Time (Quantitative) RT-PCR Analysis

Total RNA was isolated from BM or MSC using miRNeasy Mini kit (Qiagen, Valencia, Calif., USA). The gene expression in cells was determined by real time PCR using $1 \mu \mathrm{g}$ of total RNA in TaqMan Reverse Transcription reagent (Applied Biosystems, Foster City, Calif., USA). Target-specific PCR primers for VEGF-A, VEGF-R1, VEGF-R2, Runx2, peroxisome proliferator-activated receptor $\gamma$ $(\mathrm{PPAR} \gamma)$, and C/EBPa (CCAAT-enhancer-binding proteins) were obtained from Applied Biosystems. Real-time PCR amplification was performed using TaqMan Gene Expression Assays (TaqMan MGP probes, FAM dye-labeled) using Applied Biosystems ViiA7 Real-Time PCR system (Applied Biosystems). The cycle number at which the amplification plot crosses the threshold was calculated $\left(\mathrm{C}_{\mathrm{T}}\right)$, and the $\Delta \Delta \mathrm{C}_{\mathrm{T}}$ method was used to analyze the relative changes in gene expression using $\beta$-actin as a housekeeping gene [28].

\section{Calcification in vitro}

Cultured MSC were decalcified with $0.6 \mathrm{~N} \mathrm{HCl}$ for $24 \mathrm{~h}$. The calcium content of $\mathrm{HCl}$ supernatants was determined colorimetrically by the o-cresolphthalein complex one method (Calcium kit; Pointe Scientific) and normalized to protein content as previously described [29].

\section{Alkaline Phosphatase Activity}

Alkaline phosphatase activity was measured using p-nitrophenyl substrate supplied in an alkaline phosphatase assay kit (Pointe Scientific). ALP activity is normalized by protein content [30].

HIF-1 $\alpha$ Transcriptional Activity Measurement in MSC

The HIF-1 $\alpha$ activity in MSC was determined by HIF-1 $\alpha$ Transcription Factor Assay Kit (Cayman Chemical Company, Ann Arbor, Mich., USA) according to the manufacturer's instruction and normalized by nuclear protein concentration.

\section{Western Blot Analysis}

Nuclear and cytosolic protein from cultured MSC was isolated using Cayman's Nuclear Extraction kit (Cayman Chemical Company, Ann Arbor, Mich., USA) according to the manufacturer's instructions. The expression of HIF-1 $\alpha$ and Nrf2 were measured in the nuclear fraction, and the major regulator of Nrf2, Keap1 (Kelchlike $\mathrm{ECH}$-associated protein I) was measured in the cytosolic fraction by Western blot. Briefly, $30 \mu \mathrm{g}$ of nuclear or cytosolic protein was loaded on $10 \%$ SDS-PAGE and the blots were incubated with antibody against HIF-1a (1:1,000, Novus Biologicals, Littleton, Colo., USA), Nrf2 or Keap1 (1:1,000, Santa Cruz Biotechnology, Santa Cruz, Calif., USA) overnight at $4^{\circ} \mathrm{C}$ followed by incubating with peroxidase conjugated secondary antibody (1:5,000 dilution), and immunodetection with the Enhanced Chemiluminescence Prime Western Blot Detection Reagent (Amersham, Piscataway, N.J., USA). The blots were also stained for Ponceau S staining as loading control [31]. The band intensity was analyzed by ChemiDoc MP Imaging System (Imaging Lab 4.0, Bio-Rad, Richmond, Calif., USA) and normalized by Ponceau S staining.

\section{Statistics}

Statistical analysis was conducted by ANOVA and within group comparisons by Fisher's post hoc analysis. Correlations were examined by the Pearson product-moment [32]. The results are expressed as means $\pm S D$, with $p<0.05$ considered significant (StatView, SAS Institute, Cary, N.C., USA).

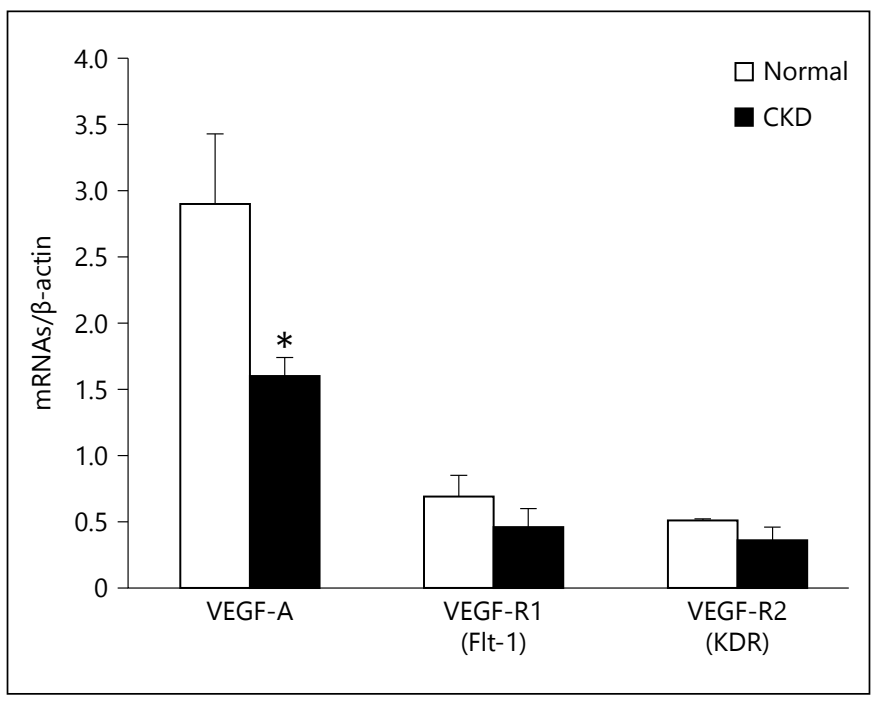

Fig. 1. The expression of VEGF-A, but not VEGF receptor 1 (Flt-1) and VEGF receptor 2 (KDR), is decreased in BM from CKD compared to normal rats: RNA expression of VEGF-A is significantly decreased in BM from CKD rat compared to normal animals. However, there is no difference in the expression of VEGF-R1 and VEGF-R2. Data are shown as mean \pm SD $(n=9$ each animal group). ${ }^{*} \mathrm{p}<0.05, \mathrm{CKD}$ compared to normal.

\section{Results}

\section{CKD Compared to Normal Animals}

VEGF-A Expression Is Lower in BM Cells from CKD Compared to Normal Animals

As shown in figure 1, VEGF-A expression was significantly lower in BM from CKD rats compared to normal animals. However, there was no difference in the expression of the receptors, VEGF-R1 and VEGF-R2.

MSCs from CKD Rats Show Reduced Mineralization and Lower Osteoblast Differentiation Along with Increased Adipocyte Differentiation

MSC derived from CKD BM had decreased alkaline phosphatase activity (fig. 2a) and reduced calcification/ mineralization (fig. 2b) compared to normal animals. In MSC from CKD animals compared to normal animals, there was increased expression of the adipogenic genes PPAR $\gamma$ and C/EBPa (fig. 3a, b) when cultured in adipogenic media, and decreased expression of the osteoblastic transcription factor Runx 2 when cultured in osteogenic media (fig. 3c). This suggests that, compared to normal animals, BM-derived MSC from CKD had reduced VEGF-A expression and impaired osteoblast differentiation and mineralization with enhanced potential for adipocyte differentiation. 


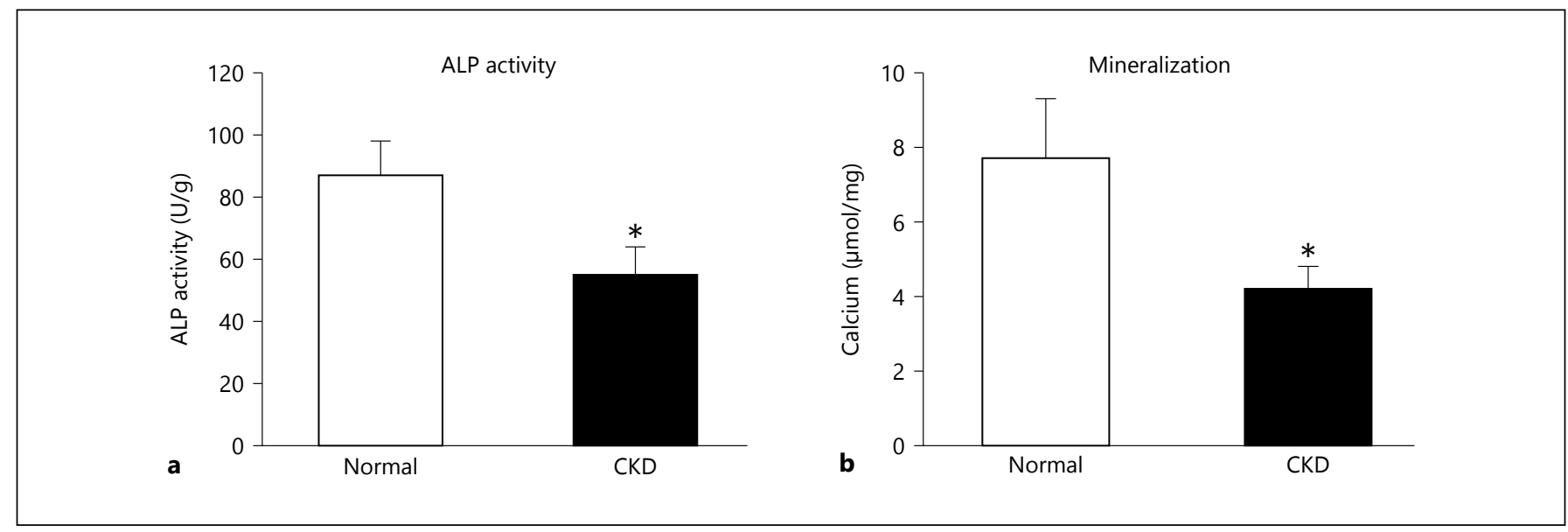

Fig. 2. MSCs from CKD rats have decreased alkaline phosphatase activity and reduced ability to mineralize: BM cell-derived MSC had decreased alkaline phosphatase activity (a) and reduced min- eralization (b) compared to normal. Data are shown as mean \pm SD ( $\mathrm{n}=4$ normal or CKD rats, with 3-cell cultures from each animal for final $\mathrm{n}=12) .{ }^{*} \mathrm{p}<0.05$, normal vs. CKD.

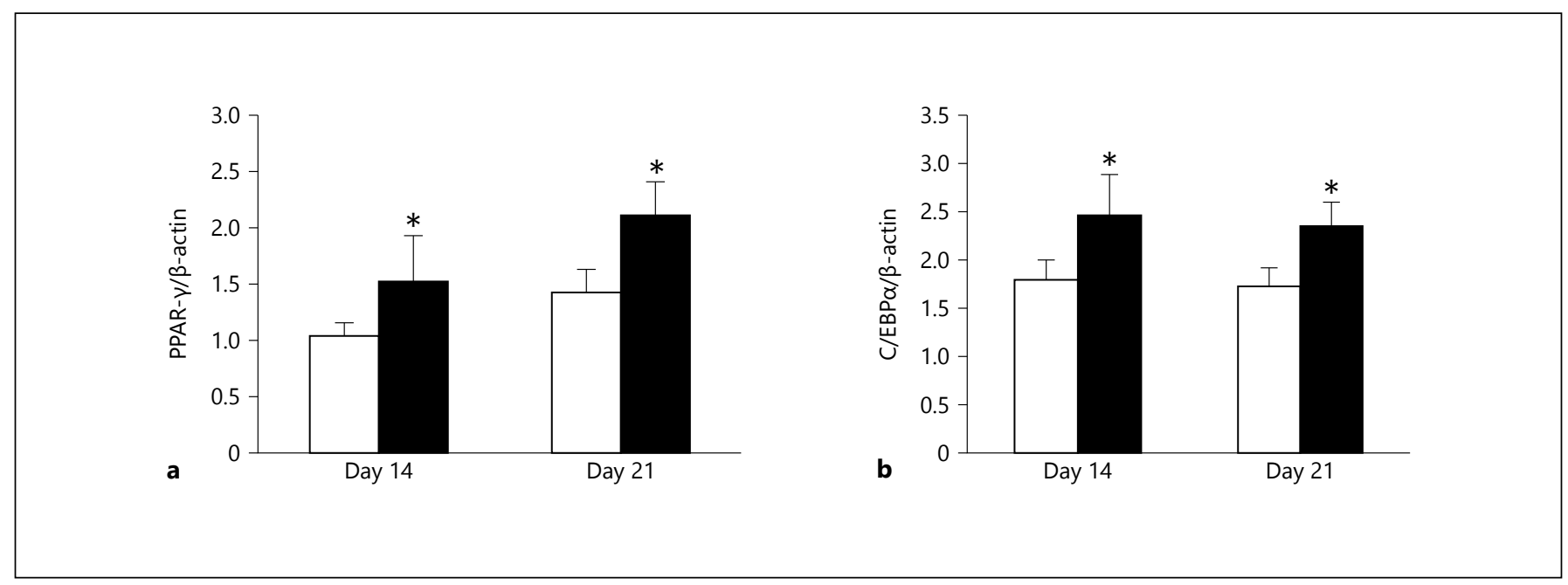

Fig. 3. MSCs isolated from CKD rats have increased adipocyte differentiation and decreased osteoblast differentiation: BM-derived cultured MSC demonstrated increased expression of adipogenic genes PPAR $\gamma$ and $\mathrm{C} / \mathrm{EBP} \alpha(\mathbf{a}, \mathbf{b})$ in MSC from CKD rats compared to that from normal rats. In contrast, the expression of the osteoblastic transcription factor Runx2 was decreased in MSC from $\mathrm{CKD}$ rats compared to normal rats (c). Data are shown as mean \pm $\mathrm{SD}(\mathrm{n}=4$ normal or CKD rats, with 3-cell cultures from each animal for final $\mathrm{n}=12)$. ${ }^{*} \mathrm{p}<0.05$, normal vs. CKD. 


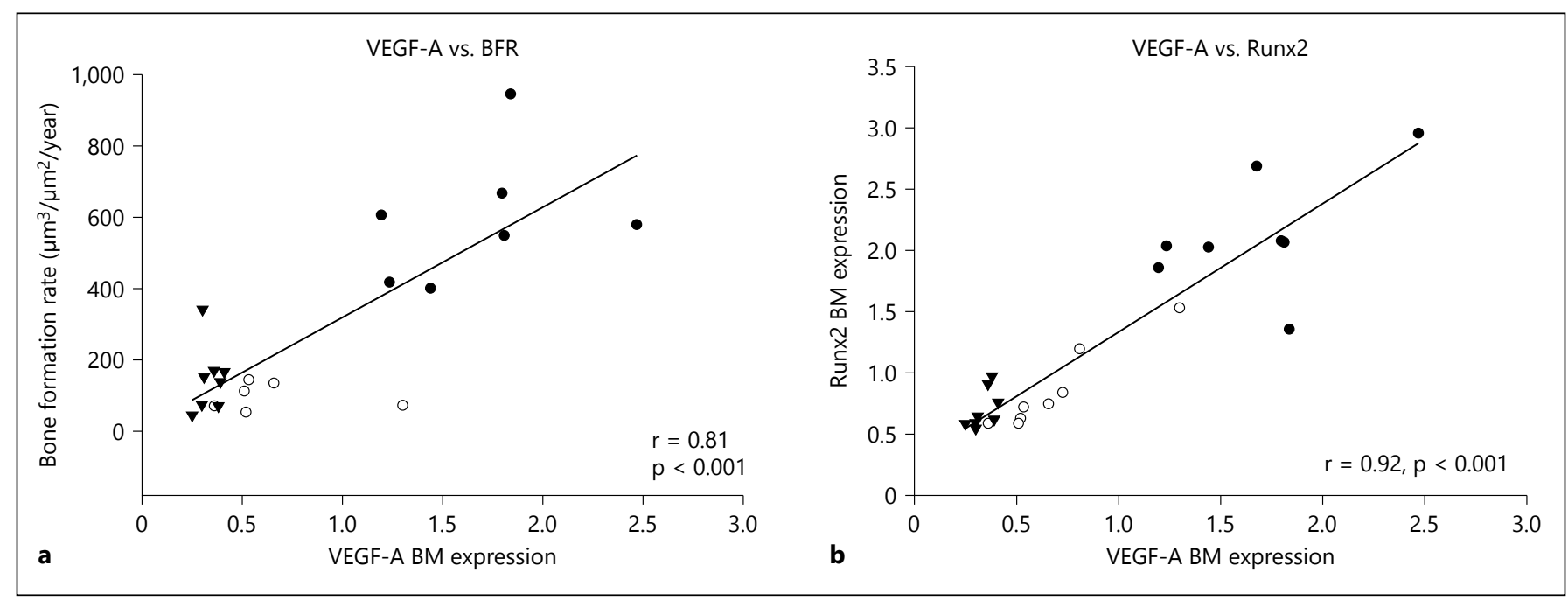

Fig. 4. The basal decrease in VEGF-A expression in BM is associated with defective MSC differentiation and low BFR in CKD rats treated with or without calcium or zoledronic acid: the expression of VEGF$\mathrm{A}$ in $\mathrm{BM}$ is positively correlated with the BFR (a). VEGF-A expression is also positively correlated with the expression of both Runx2 (b) and PPAR $\gamma(\mathbf{c})$ in BM from these CKD rats. The correlation of low VEGF-A with low expression of both Runx2 and PPAR $\gamma$ suggests an overall suppression of multiple lineages that derive from MSC. Black circles = CKD animals with high PTH, open circles = $\mathrm{CKD}$ animals with low PTH treated with calcium, black triangles = $\mathrm{CKD}$ animals treated with zoledronic acid ( $\mathrm{n}=9$ each animal group).

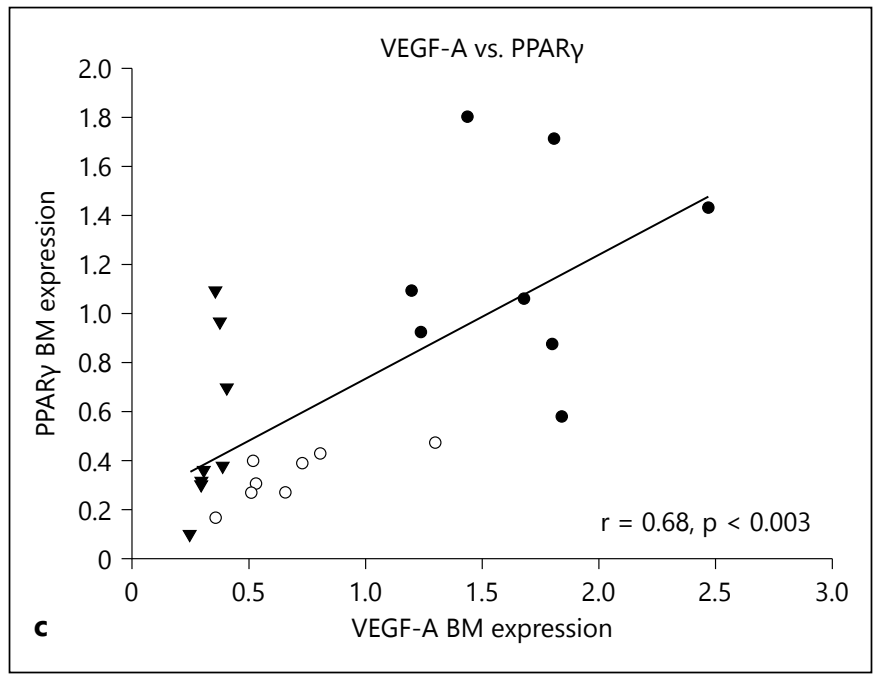

\section{CKD Animals with High vs. Low BFRs}

The Basal Decrease in VEGF-A Expression in BM Is Associated with Low Bone Formation in CKD

The expression of VEGF-A in BM cells was positively correlated with the BFR by histomorphometry $(\mathrm{r}=0.81$, $\mathrm{p}<0.001$; fig. $4 \mathrm{a}$ ) in CKD animals. VEGF-A expression in the BM cells was also positively correlated with the expression of Runx2 ( $\mathrm{r}=0.92, \mathrm{p}<0.001$; fig. $4 \mathrm{~b})$ and PPAR $\gamma$ $(\mathrm{r}=0.68, \mathrm{p}<0.003$; fig. $4 \mathrm{c})$. Similarly, the expression of Runx2 and PPAR $\gamma$ in BM cells was positively correlated with the BFR $(r=0.71, p<0.001 ; \mathrm{r}=0.53, \mathrm{p}<0.02$, respectively). Thus, the magnitude of BM cell VEGF-A expression correlated with bone formation in vivo, and the magnitude of VEGF-A expression was associated with increased mesenchymal transcription factor expression (differentiation potential). Thus, VEGF-A may be a key factor for MSC differentiation from BM cells.

The Abnormal Bone Formation and VEGF-A Expression in BM Is Independent of PTH

As shown in table 1 and previously published [1], when CKD rats were treated with calcium in the drinking water, the serum calcium is slightly increased, phosphorus is decreased and PTH is suppressed. The histomorphometry demonstrated that there is low BFR. When CKD rats were treated with zoledronic acid, the PTH is not changed but the BFR is also decreased. This model thus allows us to compare CKD animals with high BFRs and high PTH, to low BFRs with low or high PTH.

The analyses of BM cells allow us to directly relate an individual CKD animal BM to the histology. Treating CKD rats with calcium or zoledronic acid both significantly decreased VEGF-A expression in BM cells but had no effect on expression of VEGF receptors (fig. 5a). Fur- 


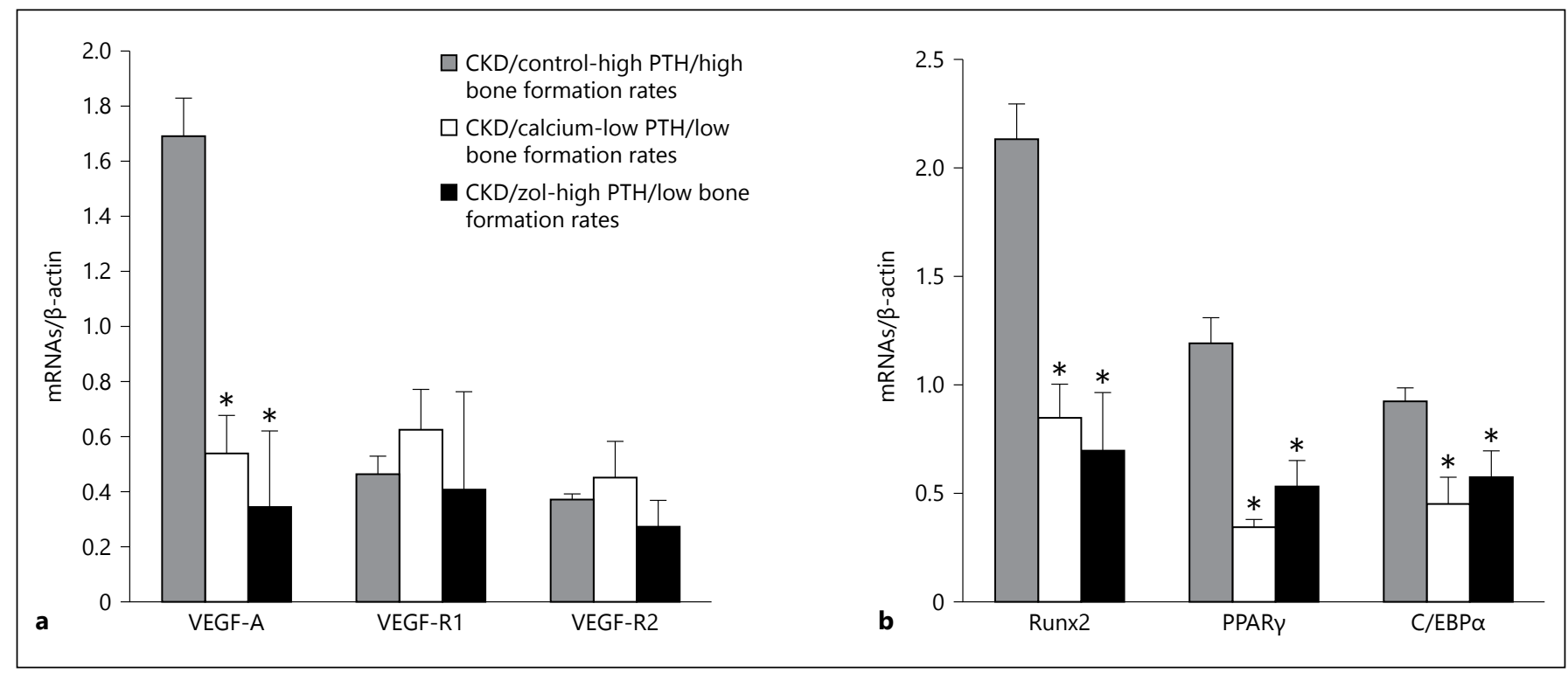

Fig. 5. The reduced VEGF-A expression in BM from animals with low bone formation in CKD is independent of PTH: BM cells from CKD rats treated with calcium (low BFRs/low PTH) or zoledronic acid (low BFRs/high PTH) were compared to control animals (high BFRs/high PTH). The results demonstrated that both low BFR groups had decreased BM cell VEGF-A RNA expression but no effect on expression of VEGF receptors (a), whereas the control

thermore, compared to untreated (high PTH) CKD rats, there was decreased expression of osteoblast transcription factor Runx2 and adipogenic transcription factors PPAR $\gamma$ and C/EBP in BM cells from CKD rats treated with calcium (low PTH) or zoledronic acid (high PTH; fig. 5b). These results suggest that in CKD animals, low BFRs are associated with both decreased VEGF-A expression in the BM cells, and reduced expression of both adiopocyte and osteogenic transcription factors, regardless of the PTH level. Thus, low BFRs are associated with impaired potential of BM cells to differentiate down the MSC lineage, perhaps the result of reduced VEGF-A expression.

\section{MSC from CKD Rats with Low PTH Have Altered}

Transcriptional Response to Hypoxia and Oxidative

Stress

We isolated BM-derived MSC (prior to differentiation) and demonstrated decreased nuclear HIF-1 $\alpha$ protein expression (fig. 6a) and activity (fig. 6b) in CKD animals treated with calcium (low BFRs and low bone turnover) compared to that in CKD control. The nuclear expression of Nrf2 (fig. 6c) was similarly decreased, and the cytosolic repressor Keap1 (fig. 6d) was increased in animals with high BFR had increased VEGF-A expression. Furthermore, compared to CKD rats with high BFR, there was decreased expression of the osteoblast transcription factor Runx2 and adipogenic transcription factors PPAR $\gamma$ and $\mathrm{C} / \mathrm{EBP} \alpha$ in $\mathrm{BM}$ cells from CKD rats with low BFR regardless of PTH (b). Data are shown as mean $\pm \mathrm{SD}\left(\mathrm{n}=9\right.$ each animal group). ${ }^{*} \mathrm{p}<0.05, \mathrm{CKD}$ vehicle vs. CKD-Zol or CKD-Ca.

these same cells. These results suggest that in the setting of CKD and low PTH, there is evidence of decreased hypoxia and oxidative stress.

\section{Discussion}

In this study, we have demonstrated that BM cells from CKD animals had decreased expression of VEGF-A compared to normal animals. When the BM-derived MSC were incubated with osteoblast or adipocyte differentiating media for 21 days, CKD-derived cells had decreased osteoblast differentiation and mineralization and increased adipocyte differentiation compared to normal derived cells. Thus, the reduced VEGF-A expression in $\mathrm{BM}$ cells and the preferential differentiation to adipocytes in culture in CKD may lead to impaired osteoblast function compared to normal animals. The BM cells represent a static measure of the composition of the marrow at the time of the biopsy, whereas the cultured cells represent the ability of the existing MSC to differentiate a specific mesenchymal lineage. Thus, our results suggest that in $\mathrm{CKD}$, compared to normal, there is both a defect in the overall mesenchymal lineage in the BM, and that the dif- 
Fig. 6. Hypoxia and oxidative stress in MSC from BM derived from CKD rats with low BFRs: MSC from CKD rats with low BFRs and low PTH had decreased HIF-1a protein expression (a) and lower HIF-1a transcriptional activity (b), compared to animals with high BFRs and high PTH. Furthermore, there is decreased Nrf2 translocation (c) to the nucleus and increased expression of Nrf2 repressor Keap1 in cytoplasm (d) in MSC from CKD rats with low bone formation compared to animals with high BFRs. The Western blot images are from 6 samples ( 3 from CKD rats and 3 from CKD rats treated with $\mathrm{Ca}$ ). Quantitative data are shown as mean \pm SD ( $\mathrm{n}=5$ rats each animal group). ${ }^{*} \mathrm{p}<0.05$, CKD vs. CKD-Ca.
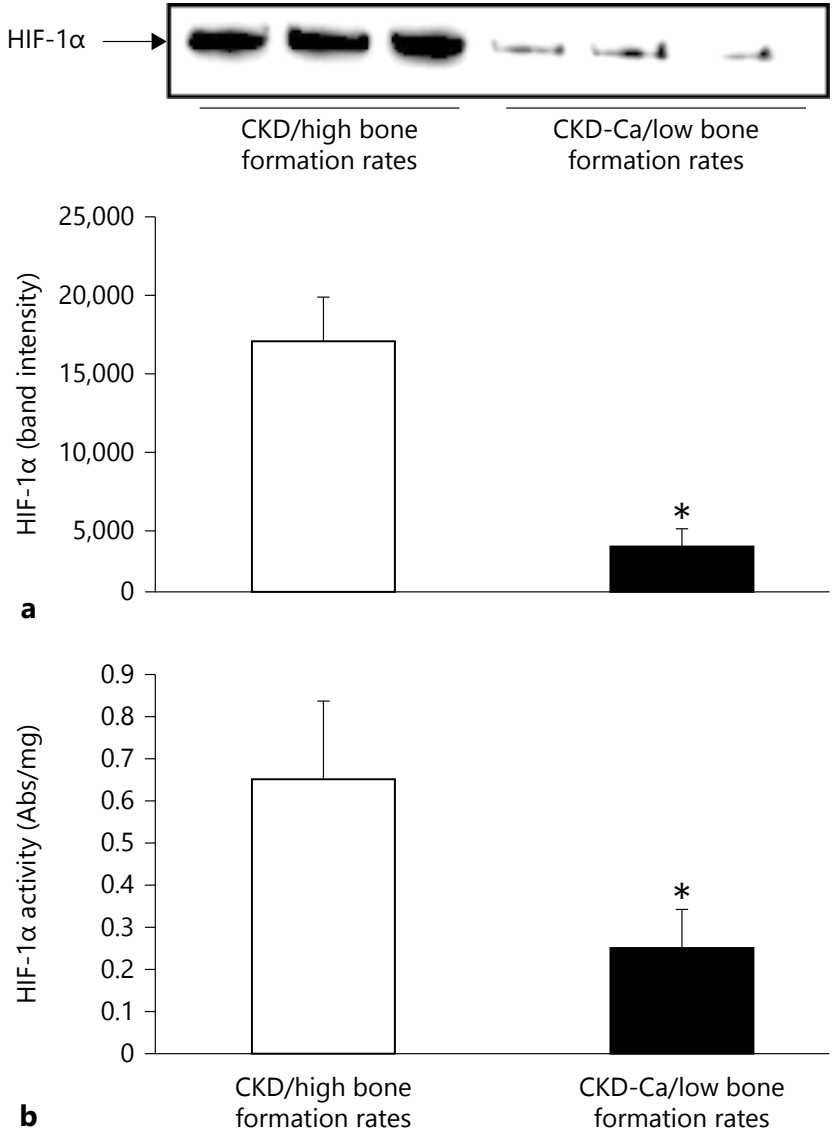

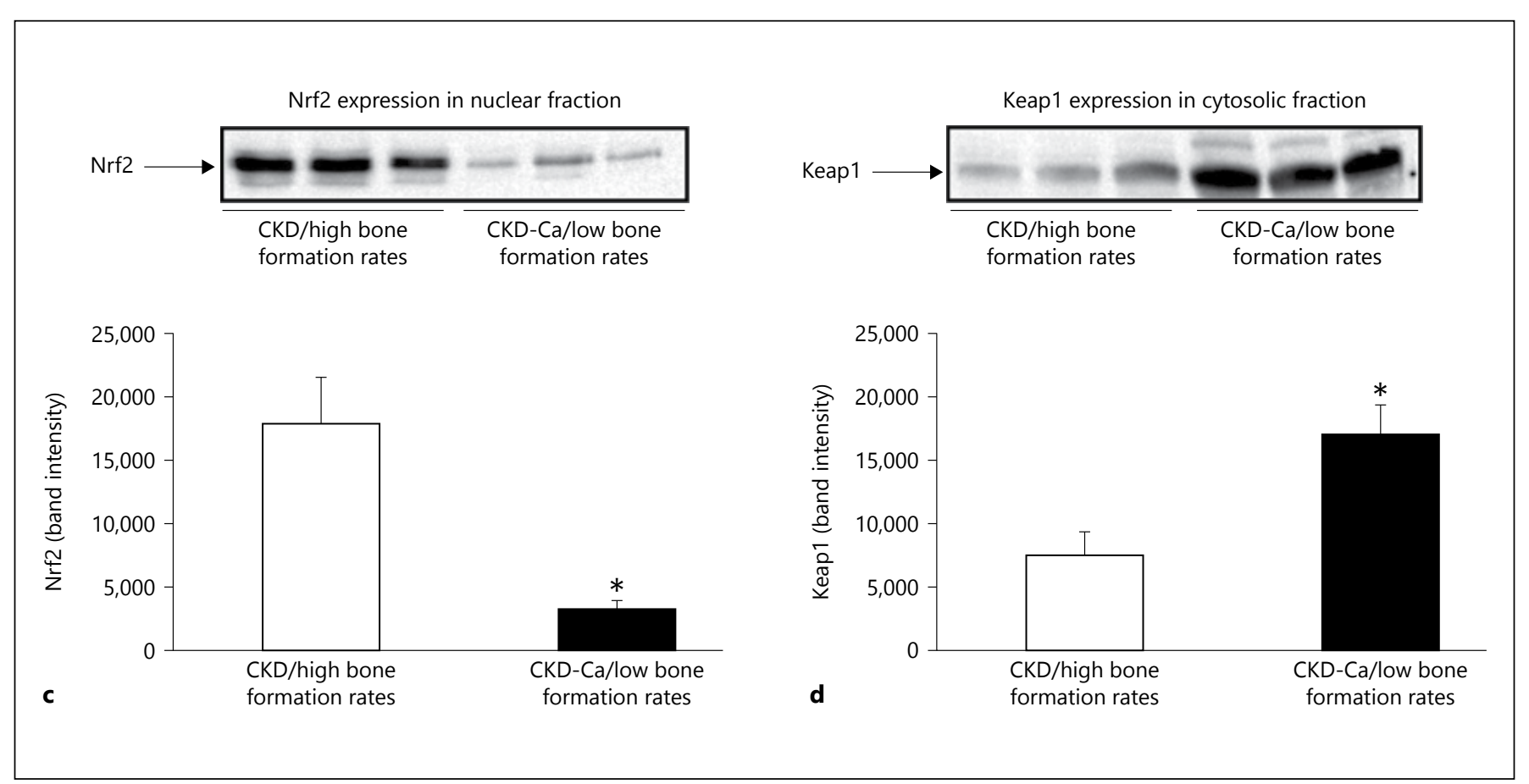


ferentiation is driven toward adipocytic rather than osteoblastic lineage.

Osteoblasts and adipocytes have a common origin in MSC with transcription factor expression driving differentiation [33]. In BM-derived MSC, there is a progressive increase in adipocyte formation and a decrease in osteoblast number with aging [34]. We have also demonstrated increased BM fat in patients with CKD compared to healthy age-, gender- and race-matched individuals [10]. Older individuals have reduced BFRs and a high fat to bone ratio in their BMs compared with young and healthy controls [35], suggesting that the control of the fates of osteoblast/adipocyte differentiation in BM MSC is important in bone formation, similar to the findings in the CKD animals in the present study. In dialysis patients, over half of bone biopsies demonstrate low BFRs [36]. While reduction, or so-called over-suppression of PTH may be one factor, this alone cannot explain why young dialysis patients with normal or even mildly elevated PTH have reduced BFRs. Impaired osteoblast differentiation due to low VEGF-A may be an alternative, or secondary, mechanism.

In CKD, there is a broad range of bone turnover phenotypes, often categorized clinically by low and high PTH [37]. However, we found that low BFRs were associated with low expression of VEGF-A and osteoblast differentiating transcription factor expression in BM cells regardless of the animal's PTH level, suggesting an inherent defect in CKD. The level of VEGF-A correlated positively with BFR, supporting the importance of VEGF-A in bone abnormalities. We further demonstrated that cultured MSC from CKD animals with low PTH had reduced expression and activity of HIF-1 $\alpha$ and Nrf2, both of which could lead to suppressed VEGF-A among other potential factors. Unfortunately, we could not assess HIF-1a and $\mathrm{Nrf} 2$ in the BM cells, or in BM/MSC from zoledronic acid-treated animals due to the limited volume of cells. Nonetheless, taken together, these results suggest that cultured MSC from CKD animals have reduced VEGF-A expression. This is associated with reduced osteoblast differentiation, perhaps due to decreased HIF- $1 \alpha$ and Nrf2, and this may contribute to low-turnover bone disease. We hypothesize that elevated PTH directly stimulates VEGF-A [16], thereby bypassing (or overcoming) this inherent defect in CKD BM differentiation. Stated differently, PTH may protect against the basal low levels of VEGF-A in BM in CKD. Additional studies where low turnover animals are given $\mathrm{PTH}$ would be required to confirm this hypothesis. The current single time point design of this study allows us only to identify associations and does not allow us to definitively assess the cause and effect of the various potential factors that may reduce VEGF-A expression in CKD.

Mice with conditional VEGF deficiency in pre-osteoblasts had reduced bone mass and increased BM fat [11]. Isolated MSC from these animals revealed impaired osteoblast and increased adipocyte differentiation [11], similar to our observations in the BM cells from CKD animals. In a previous study in mice with CKD from partial renal ablation, Noh et al. [38] showed decreased expression of VEGF-A in MSC with impaired migration and angiogenesis. Our study takes this a step further to demonstrate that the decreased expression of VEGF-A in $\mathrm{BM}$ cells, the precursors of MSC, is strongly correlated to reduced BFRs. Zoledronic acid is known to reduce cell VEGF-A expression in vitro $[32,39]$ and thus explains the reason for the reduced VEGF-A expression in zoledronic acid-treated BM cells. However, the mechanism by which CKD rats treated with calcium have lower VEGF-A expression is unknown and calcium itself may or may not be related.

We examined other pathways known to regulate VEGF-A including hypoxia and oxidative stress. Tissue hypoxia is common in CKD [40] and BM [41]. Both this study and the work of Noh demonstrated reduced HIF$1 \alpha$ in the marrow, suggesting an important role of marrow hypoxia. HIF-1 $\alpha$, induced by hypoxia, is a regulator of the expression of VEGF-A and VEGF receptors in multiple cell types [26]. Hypoxia can induce cis-acting hypoxia response elements in the VEGF gene promoter region, which contains a putative binding site for HIF-1a. In MSC, upregulation or downregulation of HIF-1a led to increased or decreased VEGF-A [26], confirming a direct regulatory effect in MSC. We further demonstrated reductions in Nrf2, a master transcription factor that responds to increased oxidative stress [42]. Nrf2 is held in the cytoplasm as an inactive complex bound to a repressor molecule Keap1, which facilitates its ubiquitination [43]. Oxidative stress leads to dissociation of Nrf2 from Keap1 and its translocation to the nucleus to activate gene expression of antioxidants. Nrf2 activation has been shown to induce VEGF expression in several cell types [44-46]. In the MSC of CKD animals treated with calcium to lower PTH, HIF-1 $\alpha$ and Nrf2 expressions were reduced and Keap1 expression was increased compared to CKD animals with high PTH. Several studies have suggested that hypoxia is closely related to oxidative stress [47]. The activation of HIF-1a reduces, whereas its inhibition worsens reactive oxygen species (ROS) generation [48]. On the other hand, oxidative stress exacerbates the 
status of hypoxia [47]. The current studies support that in $\mathrm{CKD}$, similar to aging, the impaired osteoblast differentiation is associated with reduced VEGF-A. Two possible mechanisms include altered hypoxia and oxidative stress in BM. Hypothetically, PTH can overcome, or mask, this defect by direct stimulation of VEGF-A $[16,17]$ and explain the need for supra-physiologic levels of PTH to obtain normal BFRs in CKD.

In summary, compared to normal animals, $\mathrm{BM}$ cells and MSC from CKD animals have decreased expression of VEGF-A, decreased osteoblast differentiation and mineralization and increased adipocyte differentiation. In CKD animals, BFRs directly correlate with VEGF-A levels in the BM cells. These studies support the hypothesis that CKD is a state of VEGF-A deficiency and this, in turn, leads to reduced MSC differentiation to osteoblasts, resulting in reduced BFRs. Elevated PTH may bypass this defect by directly upregulating VEGF-A. In patients with very low PTH and low turnover or adynamic bone disease, we hypothesize that upregulation of VEGF-A (perhaps by altering oxidative stress) may improve BFRs. However, our results demonstrate associations and thus additional studies are warranted to confirm this hypothesis.

\section{Acknowledgment}

This work was supported by NIH R01AR058005 (S.M.M.), NIH F30 DK10093 (C.L.N.), the Indiana Clinical and Translational Science Institute grant TR000162 (C.L.N.), and a VA Merit Award (S.M.M.).

\section{Disclosure Statement}

The authors declare that they have no conflicts of interest.

\section{References}

1 Moe SM, Chen NX, Newman CL, Gattone VH 2nd, Organ JM, Chen X, Allen MR: A comparison of calcium to zoledronic acid for improvement of cortical bone in an animal model of CKD. J Bone Miner Res 2014;29:902-910.

2 Nickolas TL, Cremers S, Zhang A, Thomas V, Stein E, Cohen A, Chauncey R, Nikkel L, Yin MT, Liu XS, Boutroy S, Staron RB, Leonard MB, McMahon DJ, Dworakowski E, Shane E: Discriminants of prevalent fractures in chronic kidney disease. J Am Soc Nephrol 2011;22:1560-1572.

3 Maravic M, Ostertag A, Torres PU, CohenSolal M: Incidence and risk factors for hip fractures in dialysis patients. Osteoporos Int 2014;25:159-165.

4 Nair SS, Mitani AA, Goldstein BA, Chertow GM, Lowenberg DW, Winkelmayer WC: Temporal trends in the incidence, treatment, and outcomes of hip fracture in older patients initiating dialysis in the United States. Clin J Am Soc Nephrol 2013;8:1336-1342.

5 KDIGO: Clinical practice guidelines for the management of CKD-MBD. Kidney Int 2009; 76:S1-S130.

6 Massry SG, Coburn JW, Lee DB, Jowsey J, Kleeman CR: Skeletal resistance to parathyroid hormone in renal failure. Studies in $105 \mathrm{hu}-$ man subjects. Ann Intern Med 1973;78:357364.

7 Bellido T: Osteocyte-driven bone remodeling. Calcif Tissue Int 2014;94:25-34.

8 Tonna S, Sims NA: Talking among ourselves: paracrine control of bone formation within the osteoblast lineage. Calcif Tissue Int 2014; 94:35-45.

9 Rosen CJ, Ackert-Bicknell C, Rodriguez JP, Pino AM: Marrow fat and the bone microen- vironment: developmental, functional, and pathological implications. Crit Rev Eukaryot Gene Expr 2009;19:109-124.

10 Moorthi RN, Fadel W, Eckert GJ, PonslerSipes K, Moe SM, Lin C: Bone marrow fat is increased in chronic kidney disease by magnetic resonance spectroscopy. Osteoporos Int 2015;26:1801-1807.

11 Liu Y, Berendsen AD, Jia S, Lotinun S, Baron R, Ferrara N, Olsen BR: Intracellular VEGF regulates the balance between osteoblast and adipocyte differentiation. J Clin Invest 2012; 122:3101-3113.

12 Gerber HP, Vu TH, Ryan AM, Kowalski J, Werb Z, Ferrara N: VEGF couples hypertrophic cartilage remodeling, ossification and angiogenesis during endochondral bone formation. Nat Med 1999;5:623-628.

13 Mayr-Wohlfart U, Waltenberger J, Hausser H, Kessler S, Günther KP, Dehio C, Puhl W, Brenner RE: Vascular endothelial growth factor stimulates chemotactic migration of primary human osteoblasts. Bone 2002;30:472477.

14 Maes C, Kobayashi T, Selig MK, Torrekens S, Roth SI, Mackem S, Carmeliet G, Kronenberg HM: Osteoblast precursors, but not mature osteoblasts, move into developing and fractured bones along with invading blood vessels. Dev Cell 2010;19:329-344.

15 Wilson A, Shehadeh LA, Yu H, Webster KA: Age-related molecular genetic changes of murine bone marrow mesenchymal stem cells. BMC Genomics 2010;11:229.

16 Rashid G, Bernheim J, Green J, Benchetrit S: Parathyroid hormone stimulates the endothelial expression of vascular endothelial growth factor. Eur J Clin Invest 2008;38:798-803.
17 Prisby R, Guignandon A, Vanden-Bossche A, Mac-Way F, Linossier MT, Thomas M, Laroche N, Malaval L, Langer M, Peter ZA, Peyrin F, Vico L, Lafage-Proust MH: Intermittent $\mathrm{PTH}(1-84)$ is osteoanabolic but not osteoangiogenic and relocates bone marrow blood vessels closer to bone-forming sites. J Bone Miner Res 2011;26:2583-2596.

18 Forsythe JA, Jiang BH, Iyer NV, Agani F, Leung SW, Koos RD, Semenza GL: Activation of vascular endothelial growth factor gene transcription by hypoxia-inducible factor 1 . Mol Cell Biol 1996;16:4604-4613.

19 Schipani E, Maes C, Carmeliet G, Semenza GL: Regulation of osteogenesis-angiogenesis coupling by HIFs and VEGF. J Bone Miner Res 2009;24:1347-1353.

20 Ruiz S, Pergola PE, Zager RA, Vaziri ND: Targeting the transcription factor Nrf2 to ameliorate oxidative stress and inflammation in chronic kidney disease. Kidney Int 2013;83: 1029-1041.

21 Brown JH, Bihoreau MT, Hoffmann S, Kränzlin B, Tychinskaya I, Obermüller N, Podlich D, Boehn SN, Kaisaki PJ, Megel N, Danoy P, Copley RR, Broxholme J, Witzgall R, Lathrop M, Gretz N, Gauguier D: Missense mutation in sterile alpha motif of novel protein SamCystin is associated with polycystic kidney disease in (cy/+) rat. J Am Soc Nephrol 2005; 16:3517-3526.

22 Taskiran EZ, Korkmaz E, Gucer S, Kosukcu C, Kaymaz F, Koyunlar C, Bryda EC, Chaki M, Lu D, Vadnagara K, Candan C, Topaloglu R, Schaefer F, Attanasio M, Bergmann C, Ozaltin F: Mutations in ANKS6 cause a nephronophthisis-like phenotype with ESRD. J Am Soc Nephrol 2014;25:1653-1661. 
23 Moe SM, Chen NX, Seifert MF, Sinders RM, Duan D, Chen X, Liang Y, Radcliff JS, White KE, Gattone VH 2nd: A rat model of chronic kidney disease-mineral bone disorder. Kidney Int 2009;75:176-184.

24 Moe SM, Radcliffe JS, White KE, Gattone VH 2nd, Seifert MF, Chen X, Aldridge B, Chen NX: The pathophysiology of early-stage chronic kidney disease-mineral bone disorder (CKD-MBD) and response to phosphate binders in the rat. J Bone Miner Res 2011;26: 2672-2681.

25 Moe SM, Chen NX, Newman Cl, Organ JM, Kneissel M, Kramer I, Gattone VH 2nd, Allen MR: Anti-sclerostin antibody treatment in a rat model of progressive renal osteodystrophy. J Bone Miner Res 2015;30:499-509.

26 Okuyama H, Krishnamachary B, Zhou YF, Nagasawa H, Bosch-Marce M, Semenza GL: Expression of vascular endothelial growth factor receptor 1 in bone marrow-derived mesenchymal cells is dependent on hypoxiainducible factor 1. J Biol Chem 2006;281: 15554-15563.

27 Caterson EJ, Nesti LJ, Danielson KG, Tuan RS: Human marrow-derived mesenchymal progenitor cells: isolation, culture expansion, and analysis of differentiation. Mol Biotechnol 2002;20:245-256.

28 Lau WL, Leaf EM, Hu MC, Takeno MM, Kuro-o M, Moe OW, Giachelli CM: Vitamin D receptor agonists increase klotho and osteopontin while decreasing aortic calcification in mice with chronic kidney disease fed a high phosphate diet. Kidney Int 2012;82:12611270.

29 Chen NX, Kircelli F, O’Neill KD, Chen X, Moe SM: Verapamil inhibits calcification and matrix vesicle activity of bovine vascular smooth muscle cells. Kidney Int 2010;77:436442.

30 Chen NX, O’Neill KD, Duan D, Moe SM: Phosphorus and uremic serum up-regulate osteopontin expression in vascular smooth muscle cells. Kidney Int 2002;62:1724-1731.

31 Romero-Calvo I, Ocón B, Martínez-Moya P, Suárez MD, Zarzuelo A, Martínez-Augustin
O, de Medina FS: Reversible Ponceau staining as a loading control alternative to actin in Western blots. Anal Biochem 2010;401:318320.

32 Li XY, Lin YC, Huang WL, Hong CQ, Chen JY, You YJ, Li WB: Zoledronic acid inhibits proliferation and impairs migration and invasion through downregulating VEGF and MMPs expression in human nasopharyngeal carcinoma cells. Med Oncol 2012;29:714720.

33 Pittenger MF, Mackay AM, Beck SC, Jaiswal RK, Douglas R, Mosca JD, Moorman MA, Simonetti DW, Craig S, Marshak DR: Multilineage potential of adult human mesenchymal stem cells. Science 1999;284:143-147.

34 Choi JH, Ke Q, Bae S, Lee JY, Kim YJ, Kim UK, Arbeeny C, Thadhani R, Kang PM: Doxercalciferol, a pro-hormone of vitamin $\mathrm{D}$, prevents the development of cardiac hypertrophy in rats. J Card Fail 2011;17:10511058.

35 Nuttall ME, Gimble JM: Is there a therapeutic opportunity to either prevent or treat osteopenic disorders by inhibiting marrow adipogenesis? Bone 2000;27:177-184.

36 Barreto FC, Barreto DV, Moysés RM, Neves KR, Canziani ME, Draibe SA, Jorgetti V, Carvalho $\mathrm{AB}$ : $\mathrm{K} / \mathrm{DOQI}$-recommended intact PTH levels do not prevent low-turnover bone disease in hemodialysis patients. Kidney Int 2008;73:771-777.

37 Sprague SM: The role of the bone biopsy inthe diagnosis of renal osteodystrophy. Semin Dial 2000;13:152-155.

38 Noh H, Yu MR, Kim HJ, Jeon JS, Kwon SH, Jin SY, Lee J, Jang J, Park JO, Ziyadeh F, Han DC, Lee HB: Uremia induces functional incompetence of bone marrow-derived stromal cells. Nephrol Dial Transplant 2012;27:218225.

39 Tang X, Zhang Q, Shi S, Yen Y, Li X, Zhang Y, Zhou K, Le AD: Bisphosphonates suppress insulin-like growth factor 1-induced angiogenesis via the HIF-1alpha/VEGF signaling pathways in human breast cancer cells. Int J Cancer 2010;126:90-103.
40 Shoji K, Tanaka T, Nangaku M: Role of hypoxia in progressive chronic kidney disease and implications for therapy. Curr Opin Nephrol Hypertens 2014;23:161-168.

41 Johnson RW, Schipani E, Giaccia AJ: HIF targets in bone remodeling and metastatic disease. Pharmacol Ther 2015;150:169-177.

42 Kim HJ, Vaziri ND: Contribution of impaired Nrf2-Keap1 pathway to oxidative stress and inflammation in chronic renal failure. Am J Physiol Renal Physiol 2010;298:F662-F671.

$43 \mathrm{Li} \mathrm{W}$, Khor TO, Xu C, Shen G, Jeong WS, Yu S, Kong AN: Activation of Nrf2-antioxidant signaling attenuates NFkappaB-inflammatory response and elicits apoptosis. Biochem Pharmacol 2008;76:1485-1489.

44 Tohidnezhad M, Wruck CJ, Slowik A, Kweider N, Beckmann R, Bayer A, Houben A, Brandenburg LO, Varoga D, Sönmez TT, Stoffel M, Jahr H, Lippross S, Pufe T: Role of platelet-released growth factors in detoxification of reactive oxygen species in osteoblasts. Bone 2014;65:9-17.

45 Afonyushkin T, Oskolkova OV, Philippova M, Resink TJ, Erne P, Binder BR, Bochkov $\mathrm{VN}$ : Oxidized phospholipids regulate expression of ATF4 and VEGF in endothelial cells via NRF2-dependent mechanism: novel point of convergence between electrophilic and unfolded protein stress pathways. Arterioscler Thromb Vasc Biol 2010;30:1007-1013.

46 Zhang Z, Wang Q, Ma J, Yi X, Zhu Y, Xi X, Feng $Y$, Jin $Z$ : Reactive oxygen species regulate FSH-induced expression of vascular endothelial growth factor via Nrf2 and HIF1a signaling in human epithelial ovarian cancer. Oncol Rep 2013;29:1429-1434.

47 Miyata T, Takizawa S, van Ypersele de Strihou C: Hypoxia. 1. Intracellular sensors for oxygen and oxidative stress: novel therapeutic targets. Am J Physiol Cell Physiol 2011; 300:C226-C231.

48 Kim JW, Tchernyshyov I, Semenza GL, Dang CV: HIF-1-mediated expression of pyruvate dehydrogenase kinase: a metabolic switch required for cellular adaptation to hypoxia. Cell Metab 2006;3:177-185. 